\title{
OS DIREITOS E O DESENVOLVIMENTO DA PERSONALIDADE DA CRIANÇA E DO ADOLESCENTE DIANTE DOS DESAFIOS NA SOCIEDADE VIRTUALIZADA
}

\author{
Daniela Menengoti Gonçalves Ribeiro \\ Autora correspondente. Universidade Cesumar (Unicesumar). Avenida Guedner, 1610 - Zona 08. Maringá/PR, Brasil. \\ CEP 87050-390. http://lattes.cnpq.br/0704785648361421. https://orcid.org/0000-0001-7621-8899. daniela.menengoti@gmail.com \\ Patrícia dos Santos Conde \\ Universidade Cesumar (Unicesumar). Maringá/PR, Brasil.
}

Considerando os efeitos da sociedade virtualizada no desenvolvimento da personalidade de crianças e adolescentes e a eficácia horizontal dos direitos fundamentais, o presente artigo analisa o reconhecimento da criança e do adolescente como sujeitos de direitos, com o objetivo de identificar se existe coincidência entre desenvolvimento da personalidade e capacidade jurídica. Para tanto, serão analisadas a personalidade jurídica, a capacidade e as perspectivas de desenvolvimento da pessoa trazidas por Jung e por Amartya Sen. Valendo-se do método dedutivo e pesquisa bibliográfica, conclui-se que a criança e o adolescente são seres humanos completos, sujeitos dos mesmos direitos humanos e da personalidade que os adultos e que têm direito a ter voz e participar de todas as decisões que os envolvam ou afetem, especialmente em questões existenciais, de acordo com sua maturidade, o que impõe uma releitura e relativização da teoria das incapacidades do Direito Civil, em razão do desenvolvimento, em especial no contexto da sociedade virtualizada, que oferece condições para que o processo de desenvolvimento da criança e do adolescente seja ainda mais veloz.

Palavras-chave: Capacidade jurídica; desenvolvimento; Carl Gustav Jung; Amartya Sen; direitos da personalidade.

THE RIGHTS AND THE DEVELOPMENT OF THE CHILD AND ADOLESCENT'S PERSONALITY IN FRONT OF THE CHALLENGES IN THE VIRTUALIZED SOCIETY

ABSTRACT

Considering the effects of the virtualized society on the personality development of children and adolescents and the horizontal effectiveness of fundamental rights, this article analyzes the recognition of children and adolescents as subject of rights, with the objective of identifying whether there is a coincidence between personality development and legal capacity. To this end, the legal personality, capacity and development prospects of the person brought by Jung and Amartya Sen will be adressed. Using the deductive method and bibliographic research, it is concluded that children and adolescents are complete human beings, subjects of the same human rights and personality rights as adults and who have the right to have a voice and to participate in all decisions that involve or affect them, especially in existential issues, according to their maturity, which imposes a re-reading and relativization of the theory of the incapacities of Civil Law, according to development, especially in the context of the virtualized society, which offers conditions for the development process of children and adolescents to be even faster.

Keywords: Legal capacity; development; Carl Gustav Jung; Amartya Sen; personality rights.

Recebido em: 13/7/2020

Aceito em: 18/10/2021 


\section{INTRODUÇÃO}

A Opinião Consultiva OC-17/02 consiste em um importante parecer da Corte Interamericana de Direitos Humanos (Corte IDH) acerca do reconhecimento da criança e do adolescente como sujeitos de direitos, e que, apesar de ter sido emitida no ano de 2002, revela-se apropriado para compreensão e solução de fenômenos que serão cada vez mais frequentes na sociedade virtualizada, tais como exposição da imagem, vazamento de dados pessoais de menores, sharenting, revenge porn, cyberbulling, pedofilia virtual e também conflitos entre pais e filhos que, mesmo incapazes, desejam afirmar sua identidade e participar das decisões relacionadas ao seu desenvolvimento.

O documento internacional também ressalta que a vontade e a opinião das próprias crianças e adolescentes devem ser ouvidas e levadas em consideração pelos pais e autoridades na definição em concreto daquilo que pode ser considerado seu melhor interesse. A Corte Interamericana de Direitos Humanos esclarece que, dentro da menoridade, existem diferentes graus de desenvolvimento e discernimento, o que implica dizer que a opinião da própria criança ou adolescente deve receber a devida importância, de acordo com sua maturidade.

Dessa forma, o presente artigo tem como objetivo estudar o reconhecimento das crianças e adolescentes como sujeitos de direitos humanos, fundamentais e da personalidade, identificando os reflexos desse reconhecimento na teoria das incapacidades do Código Civil, a fim de verificar se existe coincidência entre a capacidade jurídica e o desenvolvimento da personalidade, bem como analisar se a maioridade como requisito para a capacidade civil de exercício de direitos protege o melhor interesse da criança ou cria obstáculos à efetividade dos seus direitos da personalidade, especialmente em situações existenciais.

Para tanto, primeiro será abordado o reconhecimento internacional da criança e do adolescente como sujeitos de direitos e que devem ser ouvidos nos processos decisórios que envolvam seus direitos humanos. Na sequência, será estudada a ideia de capacidade jurídica no Direito Civil Brasileiro em contraposição com as teorias do desenvolvimento da personalidade de Carl Gustav Jung e do desenvolvimento humano de Amartya Sen. Por fim, será analisada a necessidade de releitura e relativização da maioridade na condição de critério para a capacidade civil de exercícios de direitos no que respeita às questões existenciais, especialmente no contexto da Internet, destacando os reflexos desta no desenvolvimento da personalidade e na construção da identidade de crianças e adolescentes.

Oportuno esclarecer que, no presente trabalho, o termo criança será utilizado para abranger tanto crianças como adolescentes, isto é, todos aqueles que ainda não completaram 18 anos de idade. $O$ uso generalizado do termo segue os parâmetros utilizados pela Corte Interamericana na Opinião Consultiva 17/2002, na qual o termo niños foi usado para designar conjuntamente todos os menores de 18 anos.

A pesquisa se justifica na medida em que a Internet amplia o leque de possibilidades para o desenvolvimento da personalidade e permite que esse processo se dê de forma mais acelerada, especialmente em crianças e adolescentes que, desde muito jovens e justamente no período em que as principais características da personalidade são delineadas, já vivem profundamente inseridos no universo virtual. Sendo assim, é crescente a tendência de que crianças e adolescentes reivindiquem dos adultos que suas vozes sejam ouvidas e busquem 
reafirmar sua identidade, que pode ser compreendida como o conceito que a pessoa tem de si própria individualmente e em interação com o outro, e, por isso, influencia diretamente no conteúdo dos demais atributos da sua personalidade, como a honra, a imagem e a integridade psíquica. Assim, a teoria dos direitos da personalidade deve estar atenta à criança e ao adolescente da pós-modernidade digital para que, assim, seja capaz de protegê-la e preservar sua dignidade.

Na realização da pesquisa, utilizou-se o método de abordagem dedutivo e o método de pesquisa bibliográfica, mediante a análise de livros, artigos científicos, documentos internacionais e leis brasileiras sobre o assunto.

\section{O RECONHECIMENTO DA CRIANÇA E DO ADOLESCENTE COMO SUJEITOS DE DIREITOS}

A necessidade de proporcionar à criança uma proteção especial foi enunciada na Declaração de Genebra de 1924 sobre os Direitos da Criança e na Declaração dos Direitos da Criança adotada pela Assembleia Geral da Organização das Nações Unidas (ONU) em 20 de novembro de 1959.

Em 1989 a ONU aprovou a Convenção sobre os Direitos das Crianças, na qual estabeleceu novos paradigmas de proteção à infância e à adolescência, reconhecendo-as como sujeitos de direitos titulares da proteção integral.

O artigo 12 da Convenção prevê a obrigatoriedade do Estado de garantir que a criança com capacidade de discernimento possa expressar sua opinião sobre todas as questões que Ihe digam respeito e de que essa opinião seja levada em consideração, conforme a sua maturidade e idade. Assegurou ainda à criança a oportunidade de ser ouvida nos processos judiciais e administrativos que a envolvam ou a afetem de algum modo.

Com isso, a ONU sinalizou no sentido de que, embora ainda não tenha sua capacidade de discernimento totalmente desenvolvida, a criança possui algum grau de perspicácia que Ihe permite manifestar seus próprios anseios e desejos de forma livre e racional, o que também deve produzir efeitos no mundo jurídico. $\mathrm{E}$ ao reconhecer o direito da criança à liberdade de opinião e de expressão (artigo 13), ${ }^{1}$ de pensamento, de consciência e de religião (artigo 14), ${ }^{2}$ a Convenção enfatizou que as crianças, assim como os adultos, também possuem tais atributos de sua personalidade e têm o direito de manifestá-los como forma de exercício de seu direito.

A Convenção de 1989 representou significativo avanço na transformação da visão da criança de mero objeto de proteção para sujeito de direitos. Nesse sentido, os princípios da igualdade e da isonomia inseridos no documento internacional deixaram claro que às crianças devem ser estendidos todos os direitos garantidos aos adultos, não podendo elas sofrer qualquer tipo de discriminação em razão de seu estágio de desenvolvimento. Assim, a criança foi reconhecida como ser humano já completo, com suas próprias vontades, an-

\footnotetext{
Artigo 13 - A criança tem direito à liberdade de expressão. Este direito compreende a liberdade de procurar, receber e expandir informações e ideias de toda a espécie, sem consideração de fronteiras, sob forma oral, escrita, impressa ou artística ou por qualquer outro meio à escolha da criança.

2 Artigo 14 - Os Estados-Partes respeitam o direito da criança à liberdade de pensamento, de consciência e de religião.
} 
seios, aspirações e necessidades, titulares da plenitude de todos os seus direitos humanos (RIBEIRO; ÁVILA; SANTOS, 2017).

A mudança de paradigma trazida pela Convenção de 1989 impactou significativamente no Direito Interno dos Estados, que passaram modificar leis e políticas públicas já existentes e/ou criar novas voltadas à efetivação dos direitos da criança e à primazia do seu melhor interesse. No Brasil, a Convenção foi promulgada pelo Decreto no 99.710 de 1990, por meio do qual o país assumiu, em razão da força jurídica vinculante do tratado, sua aplicação a cada criança sujeita à sua jurisdição, sem distinção alguma.

No âmbito do Sistema Interamericano de Direitos Humanos, a Opinião Consultiva OC17/2002, da Corte Interamericana de Direitos Humanos (Corte IDH), foi um dos primeiros documentos internacionais a reconhecer expressamente à criança sua condição de sujeito de direito e a ressaltar a importância de que a opinião dela seja levada em consideração na definição daquilo que representa seu melhor interesse.

A OC-17/02 foi solicitada pela própria Comissão Interamericana de Direitos Humanos após identificar que os procedimentos judiciais e administrativos de alguns países não estariam concedendo às crianças as mesmas garantias processuais asseguradas aos adultos em razão de sua menoridade, o que estaria prejudicando a efetividade dos seus direitos. Um dos principais questionamento da Comissão era voltado ao fato de que os sistemas processuais de muitos países estariam deixando de levar em consideração a vontade, a perspectiva e a opinião da própria criança na sua condição de sujeito de direitos nos procedimentos que a envolviam.

Após audiência pública com alguns Estados e entidades de proteção às crianças, a Corte reconheceu a condição da criança de ser humano completo e sujeito de direitos, de forma plena e até mesmo priorizada, reafirmando a declaração já feita no âmbito da ONU, pela Convenção sobre os Direitos da Criança de 1989.

Por outro lado, a Corte IDH também ressaltou que não raramente a definição em concreto daquilo que seria o melhor interesse da criança fica sujeita ao arbítrio das autoridades (como juízes, Conselho Tutelar, etc.), sem que sequer seja considerado aquilo que a própria criança tem por seu interesse, isto é, aquilo que ela mesma deseja e acredita ser o melhor para si, o que terá como consequência uma diminuição da efetividade dos direitos humanos dela.

A Corte IDH aponta para a necessidade de que a própria criança participe do processo de tomadas de decisão que digam respeito a ela ou a afetem, ressaltando que, dentro do próprio conceito de criança, existem diversos e muito distintos níveis de maturidade e discernimento:

Como dito anteriormente, o grupo definido como crianças engloba todas as pessoas menores de 18 anos. Evidentemente, há grande variedade no grau de desenvolvimento físico e intelectual, na experiência e na informação que possuem aqueles que estão compreendidos naquele conceito. A capacidade de decisão de uma criança de 3 anos não é igual 
à de um adolescente de 16 anos. Por isso deve-se equilibrar razoavelmente o alcance da participação da criança nos procedimentos, com o fim de garantir a proteção efetiva de seu interesse superior (CORTE..., 2002, p. 75, par. 101, tradução livre). ${ }^{3}$

O objetivo dos instrumentos e organismos internacionais era possibilitar às crianças terem voz ativa também da determinação do seu projeto de vida, "dando-lhes assim a oportunidade de lhes ser reconhecido o estatuto de sujeito de direitos" (SANI, 2013, p. 77). Segundo a Corte IDH, contudo, esse equilíbrio na participação das crianças na determinação do seu interesse superior não ocorre na maioria dos procedimentos judiciais e administrativos internos dos países americanos, nos quais é costumeiro que a voz da criança seja quase que totalmente suprimida pela voz de seus representantes.

O que se percebe é que, mesmo mais de 30 anos depois da Convenção sobre os Direitos da Criança da ONU e apesar de todo movimento internacional pelo reconhecimento da criança como sujeito pleno de direitos, ainda é muito forte a cultura do pátrio poder, marcado pela existência da figura parental forte que impõe seus interesses e suas vontades aos filhos, que só ganham voz após completarem 18 anos. Percebe-se a cultura do "enquanto você viver sob o meu teto sou eu quem defino tudo" ou do "quando você tiver 18 anos você faz o que você quiser, até lá você faz o que eu mandar"; a cultura da obediência apenas pela obediência, sem qualquer tipo de diálogo entre pais e filhos no que concerne às decisões familiares ou relativas à própria criança.

Em outras palavras, mesmo já tendo havido muitas mudanças desde as últimas décadas do século 20, elas "não foram suficientes ainda para alterar consideravelmente a posição da criança como sujeito de direitos" (SANI, 2013, p. 82). Ainda é muito marcante no emocional coletivo a ideia de que, enquanto não completar 18 anos, a criança precisa ser e fazer tudo aquilo que os pais desejam e mandam e somente após a maioridade suas vontades e opiniões passam a ter relevância. É justamente essa ideia que os organismos internacionais pretendem combater, na medida em que ela abre espaço para que os direitos que pertencem à criança sejam usurpados pelos pais, tutores e até mesmo pelas autoridades.

Pinheiro e Sousa, em pesquisa recentemente publicada, constataram a existência de uma nova forma de objetificação das crianças. Ao abordarem a efetividade no Brasil do que chamaram de direito à participação das crianças, compreendido como o direito de "ser sujeito, e não objeto, o direito de ser ouvida e compreendida, o direito de falar e ser atentamente escutada" e ainda "o direito de participar ativamente, de opinar, de expressar o que pensa, o que acha, ou como faria se pudesse compartilhar o momento de tomada de decisões a seu respeito" (2020, p. 207), identificaram que muitos daqueles que reconhecem que a criança é titular de direitos entendem que elas, por serem juridicamente incapazes, não têm condições objetivas para exercê-los (p. 209) e, por isso, esses direitos devem ser exercidos pelos pais.

Por serem intrínsecos à própria humanidade daquela (pequena) pessoa, no entanto, não se pode admitir a usurpação dos direitos humanos da criança, menos ainda de seus direi-

\footnotetext{
"Como anteriormente se dijo, el grupo definido como niños involucra a todas las personas menores de 18 años (supra 42). Evidentemente, hay gran variedad en el grado de desarrollo físico e intelectual, en la experiencia y en la información que poseen quienes se hallan comprendidos en aquel concepto. La capacidad de decisión de un niño de 3 años no es igual a la de un adolescente de 16 años. Por ello debe matizarse razonablemente el alcance de la participación del niño en los procedimientos, con el fin de lograr la protección efectiva de su interés superior".
} 
tos da personalidade, estes últimos marcados pela característica de intransmissibilidade, pelo simples fato de ainda não se ter capacidade jurídica plena. Isso também configura objetificação, como defendem os autores.

Todo ser humano já nasce dotado de personalidade plena (FERNANDES; BORCAT, 2015), mas seu discernimento é construído com passar dos anos. De acordo com Leite (2006, p. 347), a personalidade humana deve ser compreendida como um valor e, por isso, ela "não é um direito, mas um conjunto de atributos e características da pessoa humana", motivo pelo qual não se fala em direito "à" personalidade, mas em direitos "da" personalidade. Para Szaniawski (2005, p. 70), personalidade é o "conjunto de caracteres do próprio indivíduo; consiste na parte intrínseca da pessoa humana. Trata-se de um bem, no sentido jurídico, sendo o primeiro bem pertencente à pessoa, sua primeira utilidade".

Diante disso, os direitos da personalidade dão contornos ao primado da dignidade da pessoa humana e expressam os valores mais íntimos e mais caros que integram a essência da pessoa (GODINHO; GUERRA, 2013). São direitos imprescindíveis à realização da própria personalidade humana (BITTAR, 2004; BELTRÃO, 2013).

Em síntese, os direitos da personalidade podem ser compreendidos como aqueles que têm como objeto os atributos da personalidade humana, aqueles bens que são tão intrínsecos à pessoa que chegam a se confundir com ela. Sua finalidade é proteger a pessoa em sua condição de pessoa humana e em toda sua complexidade, sempre calcado no primado da dignidade.

A concepção jurídica tradicional e civilista de personalidade, todavia, não é aquela relacionada aos atributos e valores da pessoa humana em toda sua complexidade e dignidade, mas sim como aptidão para adquirir direitos e contrair obrigações, noção que está vinculada à ideia de capacidade jurídica ${ }^{4}$ e também criticada pela doutrina dos direitos da personalidade, como Fermentão (2007), para quem ela é demasiadamente simplista, reduzindo a personalidade a mero centro de imputação de direitos e deveres. Embora a personalidade inclua a imputação de direitos e deveres, ela não se limita a isso.

Borges, Souza e Lima (2016) observam que esta perspectiva da pessoa, à qual denominam de sentido formal da personalidade, está ligada à possibilidade de a pessoa exercer um papel no mundo por meio do estabelecimento de relações jurídicas. Assim, a ideia formal de pessoa estaria limitada à potencialidade de adquirir direitos e deveres e, por isso, seria incapaz de atribuir à pessoa seu valor real.

A cultura, no entanto, de que, até a maioridade, apenas os pais determinam o exercício dos direitos dos filhos, sem qualquer participação deles, atrelada ao conceito tradicional e formal civilista de personalidade, constroem um cenário de vulnerabilidade dos direitos da personalidade da criança que, para ser revertido, exige que seja questionada a relação entre capacidade jurídica e desenvolvimento da personalidade.

\footnotetext{
Ainda, segundo Tepedino e Oliva ([entre 2016 e 2020], p. 6) “Note-se que, a rigor, há dois sentidos técnicos para o conceito de personalidade. $O$ primeiro confunde-se com a noção de capacidade de gozo, associando-se à qualidade para ser sujeito de direito, conceito aplicável tanto às pessoas físicas quanto às jurídicas. O segundo, por outro lado, traduz o conjunto de características e atributos da pessoa humana, considerada como objeto de proteção prioritária pelo ordenamento, sendo peculiar, portanto, à pessoa natural".
} 


\section{CAPACIDADE JURÍDICA VERSUS DESENVOLVIMENTO DA PERSONALIDADE}

O reconhecimento de crianças e adolescentes como sujeitos de direitos humanos, fundamentais e de personalidade teve início no âmbito internacional, a partir de relevantes tratados internacionais sobre o tema, tendo sido posteriormente incorporado no ordenamento jurídico brasileiro, como mencionado anteriormente.

No Brasil, a Constituição Federal de 1988, promulgada apenas um ano antes da Convenção sobre os Direitos das Crianças na ONU, impôs já na redação original do artigo 227 o dever do Estado, da família e da sociedade de assegurar, com absoluta prioridade, o direito da criança e do adolescente à dignidade, ao respeito e à liberdade. Com isso, reforçou que às crianças também devem ser garantidos todos os direitos fundamentais previstos no artigo 5o do diploma constitucional, em observância ao princípio da dignidade da pessoa humana, insculpido no artigo 1ำ, III, da Constituição.

A Lei 8.069 de 1990, mais conhecida como Estatuto da Criança e do Adolescente (ECA), declara em seu artigo 3 o que "a criança e adolescente gozam de todos os direitos fundamentais inerentes à pessoa humana, sem prejuízo da proteção integral" e ainda assegura a eles "todas as oportunidades e facilidades, a fim de lhes facultar o desenvolvimento físico, mental, moral, espiritual e social, em condições de liberdade e de dignidade".

Em contrapartida, o artigo 3 do Código Civil prevê que o menor de 16 anos é absolutamente incapaz de exercer os atos da vida civil e o artigo 4으 do mesmo diploma dispõe que as pessoas maiores de 16 e menores de 18 anos de idade são relativamente incapazes para tanto. Desta forma, se de um lado a Constituição Federal e o ECA afirmam que a criança é titular de todos os direitos fundamentais dos quais gozam os adultos, de outro lado, o Código Civil, ao qualificá-los como relativa ou absolutamente incapazes, limita o exercício desses direitos, na medida em que muitos deles são exercidos justamente por meio de atos da vida civil.

De acordo com Borges, Souza e Lima (2016, p. 941), assim como a personalidade, o conceito de capacidade também tem dois aspectos. O primeiro deles seria a capacidade de direito, que consiste na aptidão de ser titular de direitos e obrigações, da qual toda pessoa é dotada desde o nascimento; e o segundo deles seria a capacidade de fato ou de exercício, esta compreendida como a faculdade de exercer por si mesmo esses direitos, estando, desse modo, intrinsecamente ligada à maioridade.

Assim, aquele que ainda não possui capacidade plena de exercício em razão da menoridade, exerce seus direitos representado ou assistido pelos pais. É o que preveem os artigos 1.630 e 1.634 , VII, do Código Civil, por força dos quais os filhos ficam sujeitos ao poder familiar enquanto menores e um dos poderes/deveres que integram o poder familiar é justamente a representação dos filhos antes dos 16 anos e assistência dos 16 aos 18 anos de idade, tanto judicial quanto extrajudicialmente.

Nesse momento é possível - e até provável - que alguém diga que, devido aos institutos da representação e da assistência, o Código Civil não limita o exercício dos direitos pelas crianças e adolescentes, porque eles os exercem por meio da representação ou assistência dos pais. Tal afirmação está apenas parcialmente correta. De fato, os menores podem exercer os atos da vida civil representados ou assistidos pelos pais, mas que garantia se tem de que a vontade expressa pelos pais em nome dos filhos efetivamente é a mesma vontade que os fi- 
Ihos expressariam caso falassem por si próprios? Será que, antes de representar ou assistir os filhos, os pais sempre oportunizam a fala deles e levam em consideração aquilo eles expressam como sendo seu interesse?

Muitos responderiam negativamente à pergunta e não veriam qualquer problema nisso. Afinal, a criança é apenas uma criança e não tem condições de saber o que é bom ou ruim para ela, cabendo somente aos pais decidir. E aqui vem novamente à tona a questão - e o problema - da crença de que a criança, devido ao simples fato de ainda não ter capacidade jurídica civil plena, supostamente também não tem capacidade psíquica, intelectual e de experiência para compreender suas próprias vontades e refletir sobre seus próprios interesses.

O regime das incapacidades no Brasil, de acordo com Tepedino e Oliva ([entre 2016 e 2020], p. 8), parte do pressuposto de que as crianças, os menores de idade, são desprovidos de discernimento para a prática de atos em geral. Logo, são impedidos de exercer por si próprios todos os seus direitos como uma forma de protegê-los de possíveis danos.

O critério adotado pela teoria das incapacidades é, desse modo, um critério objetivo pautado em um marco temporal (idade): não tem discernimento aquele que ainda não completou 18 anos de idade; completados 18 anos, a pessoa passa a ter discernimento. 0 critério objetivo da idade, entretanto, revela-se falho diante dos diferentes níveis de maturidade e de desenvolvimento que podem existir entre 0 e 17 anos de idade, como ressaltado pela Corte Interamericana de Direitos Humanos na Opinião Consultiva 17/2002.

O discernimento é construído de forma gradual, com o passar do tempo e a vivência de experiências pela criança. Por isso, é inquestionável que um jovem que acabou de completar 18 anos e 1 dia de idade tem a mesma maturidade e discernimento que ele possuía quando contava com 17 anos, 11 meses e 29 dias de idade (apenas 2 dias antes). No primeiro caso, contudo, ele está legalmente autorizado a exercer livremente todos os seus direitos e no segundo não, como se o desenvolvimento necessário para autodeterminar os próprios interesses fosse repentina e magicamente adquirido pelo aniversário.

Dessa forma, a teoria das capacidades e incapacidades urge ser confrontada com a ideia de desenvolvimento humano, especialmente no que diz respeito ao exercício dos direitos da personalidade, direitos personalíssimos e intransmissíveis mesmo aos pais durante a menoridade e que inevitavelmente se ligam a situações existenciais, e não puramente patrimoniais. Para tanto, oportuno trazer à tona os pensamentos e as perspectivas do psiquiatra analítico Carl Gustav Jung e do economista Amartya Sen sobre o desenvolvimento.

\subsection{O desenvolvimento psíquico da personalidade segundo Jung}

Carl Gustav Jung foi um psiquiatra suíço que se propôs a estudar os conceitos de personalidade introvertida e personalidade extrovertida, bem como os arquétipos e o inconsciente humano. Jung foi a criador da Psiquiatria analítica e um estudioso da interação entre o inconsciente e o consciente. Por essa razão, dedicou muito do seu estudo à compreensão dos sonhos e ao desenvolvimento da personalidade, marcada por um processo de tomada de consciência de si próprio. Seus discípulos, chamados neojunguianos, também aprofundaram os estudos sobre a infância. 
Pedersoli (2018, p. 49) afirma que Jung "foi um dos precursores na teoria do desenvolvimento por ver um caráter progressista no desenvolvimento da personalidade" e por considerar que "o indivíduo se desenvolve ao mesmo tempo em que desenvolve o meio em que vive. Ele é influenciado e influencia o meio no processo de desenvolvimento" (p. 50).

Jung defendia que a criança nasce em um estado inicial de inconsciência que se assemelha muito ao estado de inconsciência do animal e, a partir dele, vai se desenvolvendo até criar primeiro uma consciência primitiva de si mesma e depois uma consciência civilizada (JUNG, 2011). Segundo ele, esse processo tem maior intensidade a partir do nascimento até o final da puberdade psíquica, que ocorre por volta dos 25 anos nos homens e dos 19 anos nas mulheres. Nesse período ocorre um salto no desenvolvimento da consciência do indivíduo, tornando-o mais maduro e mais consciente de si e do universo ao seu redor (JUNG, 2011).

Dessa conclusão junguiana já é possível extrair uma das primeiras críticas ao sistema das capacidades civis. Se um indivíduo só adquire maior consciência de si e do mundo ao seu redor ao final da puberdade psíquica e esta só acontece aos 19 anos de idade para as mulheres e aos 25 anos para os homens, conclui-se que uma pessoa com 18 anos idade, seja homem ou mulher, ainda não tem sua consciência suficientemente madura. Logo, não se poderia presumir que aos 18 anos ela teria discernimento suficiente para exercer por si mesmo todos os atos da vida civil, como pressupõe a teoria das capacidades.

Indo além, Jung afirma que o desenvolvimento total da personalidade exige a vida toda de uma pessoa em todos os seus aspectos. Para ele, "personalidade é a realização máxima da índole inata e específica de um ser vivo em particular" e ainda a "obra a que se chega pela máxima coragem de viver, pela afirmação absoluta do ser individual, e pela adaptação, a mais perfeita possível, a tudo que existe de universal, e tudo isso aliado à máxima liberdade de decisão própria" (2011, p. 151-152). Por isso, nem sempre um indivíduo atinge o nível máximo do desenvolvimento da personalidade, mas, mesmo assim, é dada a ele a capacidade e autonomia para autodeterminar o exercício dos seus direitos da personalidade. ${ }^{5}$

De acordo com Ramos, a Psicologia Analítica fundada por Jung tem como eixo central o processo de individuação, que consiste no processo em que o ser humano busca conhecer a si mesmo, tanto por meio do autoconhecimento propriamente dito quanto mediante a integração com os outros e com o mundo espiritual. "Trata-se da busca pela totalidade psíquica (a integração entre consciente e inconsciente)" (2002, p. 128).

O autor também ressalta que não há garantias de que, mesmo na senilidade, o sujeito algum dia concluirá seu processo de individuação e a vivência do self; pelo contrário, a maioria das pessoas não conclui esse processo. Essa busca depende de fatores internos e externos à pessoa, estes últimos envolvendo "possibilidades e limites dados pelo meio em que o indi-

\footnotetext{
De acordo com Cantalli (2009), a tutela dos direitos da personalidade pode ser tanto negativa quanto positiva. A tutela negativa está ligada a uma ideia de abstenção, ou seja, de impedir que os direitos da personalidade de um indivíduo sejam violados por terceiros. Já a tutela positiva está vinculada à ideia de autonomia, isto é, para realmente efetivar seus direitos da personalidade, o sujeito deve ter autonomia para definir como ele quer exercê-los, para autodeterminar o desenvolvimento da sua personalidade, ainda que isso implique certa disposição dos seus direitos, mas desde que não fira o núcleo essencial da dignidade. A discussão se as crianças teriam autonomia para dispor de seus direitos da personalidade é demasiadamente complexa e ultrapassa os limites propostos para o presente trabalho; contudo, a tutela positiva dos direitos da personalidade que também deve ser garantida às crianças envolve, no mínimo, o direito delas de dizerem como querem exercer esses direitos e de terem sua voz escutada e levada em consideração pelos pais e autoridades.
} 
víduo vive" e nela "o indivíduo aprende através de suas próprias experiências, 'acertando' e 'errando', enfrentando seus 'anjos' e 'demônios'” (2002, p. 128).

Sendo assim, a personalidade, que já existe na criança, desenvolve-se aos poucos no curso da vida, conforme o ser vai ganhando determinação, inteireza e maturidade. E, de acordo com Jung, desde muito jovem a criança sente a necessidade de se tornar independente da psique dos pais, e essa luta por independência para se chegar ao total desenvolvimento da personalidade tem início já na escola. Segundo Pedersoli (2018), na teoria junguiana é importante que já na primeira fase da vida o sujeito rompa com seus aspectos mais infantilizados para, assim, avançar no seu desenvolvimento.

Assim, Jung (2011) ressalta que a vida psíquica de uma pessoa varia conforme sua idade se modifica e, por essa razão, crianças não têm a mesma vida psíquica de adultos. Nesse sentido, deve ser oferecidos a elas espaço e liberdade para que sua personalidade possa se desenvolver sem estar presa demais à família, sob pena de elas se tornarem jovens incapazes de assumirem as próprias responsabilidades e se acomodarem no mundo. A criança precisa tomar consciência de si e descobrir o que deseja de verdade, necessidade que a ela seja oportunizado "escolher seu próprio caminho, de maneira consciente e por uma decisão consciente e moral" (JUNG, 2011, p. 154). Por isso alerta:

Se é falta de sorte da criança não encontrar uma verdadeira família em casa, de outro lado também é perigoso para a criança estar presa demais à família. A ligação muito forte aos pais constitui impedimento direto para a acomodação futura no mundo. $\mathrm{O}$ adolescente está destinado ao mundo, e não a continuar a ser sempre apenas filho de seus pais. Lamentavelmente há muitíssimos pais que persistem em considerar os filhos sempre como crianças, porque eles próprios não querem nem envelhecer, nem renunciar à autoridade e ao poder de pais. Agindo desse modo, exercem sobre os filhos influência altamente desastrosa por tirar-Ihes todas as ocasiões de assumirem responsabilidade individual. Esse método prejudicial ou produz pessoas sem independência própria ou indivíduos que forçam a conquista da própria independência por caminhos escusos. Em contrapartida, há também outros pais que, por causa de sua própria fraqueza, são incapazes de opor à criança aquela autoridade da qual precisará mais tarde para adaptar-se corretamente ao mundo (JUNG, 2011, p. 49).

O excerto anterior pode ser compreendido como um alerta de Jung sobre a postura de autoritarismo ou de apego por vezes assumida pelos pais, na qual também está incluído o costume de não ouvir a voz ou não levar em consideração as próprias vontades e interesses da criança. Esta, conforme sua idade, possui certo grau de consciência e desenvolvimento psíquico que lhe permite assumir responsabilidades e assim adquirir mais consciência e maturidade, o que deve ser levado em consideração pelos pais. A ela deve ser dada a liberdade para se desenvolver e se autodeterminar de acordo com seu grau de consciência como parte necessária do processo de desenvolvimento da personalidade.

Diante disso, conclui-se que, na perspectiva psicológica, mais precisamente da Psicologia Analítica de Jung, o desenvolvimento psíquico e da personalidade não guarda qualquer correspondência com a ideia da capacidade de exercício civil de direitos e com a idade de nascimento propriamente dita. Pelo contrário, constata-se que a personalidade de um sujeito pode nunca se desenvolver completamente, mas, mesmo assim, é necessário que desde a infância já seja garantida à criança certa liberdade para fazer suas escolhas, cometer seus erros 
e acertos e ir se desvinculando da psique dos pais e das condições infantilizadas da vida. Só assim ela terá condições de ser um adulto mais psicologicamente saudável.

\subsection{A ideia de desenvolvimento humano na perspectiva de Amartya Sem}

Amartya Sen é um economista e filósofo indiano, graduado em Economia pela Universidade de Calcutá e em Filosofia em Cambridge, e que em 1998 recebeu o Prêmio Nobel em Ciências Econômicas por ter criado, em parceria com Mahbub ul Haq, o Índice de Desenvolvimento Humano (IDH), que representou uma nova forma de avaliar o desenvolvimento dos países pautada não apenas no crescimento econômico, mas também em fatores sociais. $\mathrm{Na}$ visão de Sen, o desenvolvimento não se liga apenas ao consumo, Produto Interno Bruto (PIB) e outras questões econômicas, mas também à liberdade dos seus cidadãos, as quais ele classificou como liberdades constitutivas e liberdades instrumentais.

Pompeu e Melo (2016) esclarecem que, para Sen, a liberdade substantiva pode ser compreendida como a ligação entre desenvolvimento e capacidades. Assim, as liberdades substantivas são as liberdades mais elementares da vida humana, como liberdade de participar da política, de se expressar, liberdade de evitar privações e que os direitos sejam violados, liberdades estas que pressupõem certa capacidade. Já as liberdades instrumentais, continuam os autores, são aquelas necessárias para o desenvolvimento das liberdades substantivas, são as oportunidades que ajudam as pessoas a desenvolverem suas capacidades e, assim, serem substancialmente livres, tais como facilidades econômicas, oportunidades sociais, segurança, educação, assistência médica, etc.

Nesse contexto, Zambam (2009) aponta que, para Amartya Sen, a pobreza e as tiranias que podem assolar a vida humana diminuem a participação do indivíduo na vida social e representam formas de negação da sua plena realização humana. Por isso é importante que existam oportunidades para possibilitar às pessoas o ato de escolha. Sen considera que só é efetivamente livre aquele a quem são dadas as condições mínimas que possibilitem o exercício real da liberdade:

O desenvolvimento humano deve ser sobretudo um aliado dos pobres, e não dos ricos e abastados. O que o desenvolvimento humano faz? A criação de oportunidades sociais contribui diretamente para expansão das capacidades humanas e da qualidade de vida. A expansão dos serviços de saúde, educação, seguridade social, etc., contribui diretamente para a qualidade da vida e seu florescimento (SEN, 2010, p. 191).

Dessa forma, a teoria do desenvolvimento de Sen tem como pressuposto a liberdade como elemento essencial para o desenvolvimento. Desse modo, para tornar o desenvolvimento possível, é necessário antes eliminar os elementos que privam os indivíduos de suas liberdades, tais como a pobreza e as tiranias, conforme já mencionado. E a liberdade substantiva inclui a capacidade do indivíduo de escolher o modo de vida que ele quer viver e que valoriza.

Amartya Sen também defende que, embora exista uma responsabilidade do Estado e da sociedade para com o indivíduo, o indivíduo também deve ter a responsabilidade e a liberdade de zelar por seus próprios interesses, assumindo a responsabilidade por suas preferências, mantendo sua motivação e evoluindo no sentido do seu autoconhecimento. 
Explica que desenvolvimento pressupõe liberdade, que, por sua vez, não existe sem responsabilidade. Quanto mais liberdade uma pessoa tem, mais ela pode desenvolver-se e perseguir a vida que deseja e na qual sentir-se-á feliz. Esse conjunto capacitário de uma pessoa é - leque de capacidades que ela dispõe para seguir a vida que valoriza, a liberdade que possui para escolher o modo pelo qual quer conduzir e viver sua vida.

O poder de escolha em Sen, de acordo com Zambam é um dos elementos mais valiosos para a pessoa inserida na sociedade e consiste em "ter condições de participar efetivamente dos seus destinos e contribuir para o seu desenvolvimento" (2009, p. 61). Como consequência, a sociedade deve dar condições para que o indivíduo possa realizar as escolhas que ele considera importantes, tornando o agir humano mais abrangente e, assim, enriquecendo a identidade do sujeito, uma vez que, no contexto de uma sociedade tão plural como a da atualidade, cada sujeito tem diante de si diversas alternativas e a escolha por uma delas deve refletir aquilo que ele considera valioso por motivos de ordem pessoal, cultural e/ou social.

E aqui, no âmbito da importância da liberdade para o desenvolvimento e afirmação da identidade, convém novamente citar Jung (2011), que chama a atenção para os perigos de uma personalidade pequena e frágil, dotada de voz imprecisa, que pode acabar de confundindo com a sociedade e tendo a voz interior substituída pela voz do grupo social e de suas designações, em prejuízo das reais e mais profundas aspirações do sujeito.

Retomando a análise de Zambam sobre Sen, o autor continua dizendo que, pela liberdade, o indivíduo "tem condições de efetivar as suas escolhas, constituir a sua identidade individual e as relações que considera indispensáveis para a sua realização e as suas condições de vida" (2009, p. 60). E o desenvolvimento das capacidades que é possibilitado pela liberdade dá as "condições necessárias para que a pessoa participe livremente, pelas opções que realiza, dos diferentes espaços existentes na sociedade sem qualquer tipo de constrangimento ou de discriminação" (ZAMBAM, 2009, p. 60). À pessoa deve ser garantida a possibilidade formal e material de agir livremente e fazer as escolhas que ela considerar importantes.

As condições para o desenvolvimento das capacidades e a liberdade para fazer as escoIhas que deseja, entretanto, não configuram via de mão única, que apenas beneficia o sujeito. A perspectiva de Amartya Sen sobre os direitos humanos é uma perspectiva universalista na qual todos são chamados a também cooperar para o desenvolvimento e para a efetivação dos direitos humanos do todo. Em outras palavras, o sujeito livre e que se desenvolve a partir das condições que lhes foram dadas pelo meio tem o dever de também contribuir com o desenvolvimento do todo e com a ampliação das liberdades dos demais; ele possui uma responsabilidade social.

A existência de um ciclo interativo entre o indivíduo e o meio também é ressaltada por Jung, que afirma que ao mesmo tempo em que o indivíduo depende do meio para se desenvolver, à medida que ele se desenvolve, ele também desenvolve o meio. Logo, a perspectiva psicológica do desenvolvimento está intimamente ligada à perspectiva sociológica do desenvolvimento e ambas possuem um requisito essencial comum para existir: liberdade. 


\section{A NECESSÁRIA RELEITURA DA TEORIA DAS INCAPACIDADES EM RAZÃO DO DESENVOLVIMENTO E O MUNDO VIRTUALIZADO}

No tópico anterior foi demonstrado que, tanto da perspectiva psicológica (Jung), quanto da perspectiva sociológica (Sen), é importante que seja dado ao indivíduo liberdade para que ele possa buscar o próprio desenvolvimento psicológico e de suas capacidades, fazer suas próprias escolhas, se diferenciar do todo, e, assim, tornar-se um adulto com a psique saudável e que é capaz de contribuir com a sociedade, colaborar para o desenvolvimento do meio em que ele se encontra. Essa liberdade deve ser garantida desde a infância, o que implica dizer que a criança deve ter liberdade de participar daquilo que diz respeito a seus direitos, especialmente nas situações existenciais, o que revela a necessidade de que o critério da maioridade para determinar a capacidade de exercer os direitos seja questionado, especialmente no que respeita às questões existenciais.

Machado e Nilson (2016, p. 53) apontam que o critério da idade (18 anos) para determinar a plena capacidade de exercício dos direitos é pautada em uma presunção legal de discernimento, ou seja, presume-se que o atingimento da maioridade aos 18 anos "faz raiar a plena aptidão ao autônomo exercício de situações jurídicas subjetivas" e que, antes disso, as pessoas são em tese total ou parcialmente incapazes de agir por si mesmas por serem "destituídas no todo ou em parte da compreensão e juízo necessários para reger pessoalmente seus interesses".

Ficou demonstrado, todavia, no tópico anterior que, na perspectiva psicológica, o desenvolvimento psíquico não guarda correspondência direta com a idade de nascimento, de maneira que é falsa a presunção de que antes dos 18 anos uma pessoa não tem a compreensão e o juízo necessários para identificar e reger seus interesses nem de que a partir dos 18 anos essa compreensão e esse juízo são magicamente adquiridos. O desenvolvimento da personalidade e do discernimento é gradual e se inicia já na infância.

Desse modo, a presunção de desprovimento de compreensão e juízo dos menores de idade que marca o regime civil das incapacidades foi forjada e fazia sentido no contexto de um Direito Civil patrimonialista (BORGES; SOUZA; LIMA, 2016), que partia do pressuposto de que as crianças, justamente por ainda serem sustentadas pelos pais, ainda não tinham experiência e autonomia suficientes para escolher o que gostariam de fazer com seus bens. Tepedino e Oliva (2016) ressaltam que, no passado, no sentido tradicional de personalidade (capacidade para ser sujeito de direito e obrigações), seria possível fazer essa distinção entre as noções de personalidade e de capacidade.

Na mesma perspectiva, Machado e Nilsson, ressaltam que, embora aceitável nas situações patrimoniais, a restrição da capacidade de exercício de direitos dos menores de 18 anos e o instituto da representação pelos pais não podem ser integralmente admitidos nas situações existenciais:

Para um incapaz de agir, sob a ótica do regime jurídico forjado pelo direito civil tradicional segundo o paradigma patrimonialista, os institutos de suprimento da incapacidade de exercício (representação e assistência) seriam adequados para sua proteção no tráfego negocial por meio da substituição ou confluência de vontade do representante ou assistente na prática de atos jurídicos. É dizer: ao incapaz é atribuída a titularidade da situação subjetiva (patrimonial), enquanto o exercício é entregue ou depende da participação as- 
sertiva de outrem. Salta aos olhos que esse esquema jurídico não pode ser transplantado para a esfera das situações jurídicas existenciais, pena de ferir a própria relevância prática da titularidade destas por incapazes de agir, uma vez que têm caráter personalíssimo (MACHADO; NILSSON, 2016, p. 66-67).

A transformação do Direito Civil clássico no sentido de afastá-lo de uma postura centrada no patrimônio para adotar como núcleo normativo a pessoa humana deu-se em razão do processo ao qual se deu o nome de repersonalização do Direito Civil. Por meio dele o Direito Civil passou a contemplar também questões existenciais, que dizem respeito ao modo de ser e de viver da pessoa, em toda sua complexidade, a partir do reconhecimento da dignidade da pessoa humana como direito fundamental e núcleo de todo o ordenamento jurídico. ${ }^{6}$

Esse movimento teve início após a Segunda Guerra Mundial e as Constituições que surgiram nesse período preocupavam-se em proteger o ser humano como ser dotado de dignidade e, para isso, passaram a tratar e regular situações que antes eram restritas ao Direito Privado. A valorização da dignidade da pessoa humana e a colocação da pessoa como núcleo essencial do ordenamento jurídico provocou a repersonalização do Direito Privado, "abandonando-se a ideia de simples protetor dos interesses patrimoniais para tutelar o patrimônio apenas como um suporte ao livre desenvolvimento da pessoa (CANTALLI, 2009, p. 53).

Desta forma, a partir da repersonalização do Direito Civil, a pessoa não pode mais ser vista como mero centro de imputação de direitos e deveres. Pelo contrário, deve ser vista em toda a sua complexidade, como "o ser humano que chora, se alegra, tem vontades, desejos" (FERNANDES; BORCAT, 2015, p. 86-87), que têm relevância jurídica e que demandam sua tutela nas questões existenciais, diversamente do que ocorre no Direito Obrigacional e nos Direitos Reais, mais ligados às questões patrimoniais. Logo, conforme destacam Bolesina e Schroeder (2016, p. 6), atualmente, quando se discute direitos humanos e/ou da personalidade, deve sempre se ter como ponto de partida a complexidade da pessoa humana.

Borges, Souza e Lima ressaltam que a constitucionalização e repersonalização do Direito Civil tornou insuficientes os conceitos de maioridade e capacidade para atender com efetividade os interesses existenciais da pessoa; por isso, defendem que seja reconhecida aos menores de idade "a titularidade de algum grau de autonomia jurídica que decorre diretamente de sua condição de pessoa, de sua dignidade, independentemente de menoridade ou de eventual processo de interdição", pois mesmo sendo formalmente incapazes, eles "são dotados de autonomia jurídica para participar dos processos decisórios quanto às questões que afetem sua dignidade, seu modo de ser, seus interesses existenciais" (2016, p. 941).

Assim, de acordo com os autores (BORGES; SOUZA; LIMA, 2016, p. 942), a limitação legal da capacidade jurídica deve ser flexibilizada para refletir de forma efetiva a proteção in-

\footnotetext{
${ }_{6}$ A Alemanha foi um dos primeiros países a consagrar a dignidade da pessoa humana como direito fundamental. Em 1949, apenas um ano depois da aprovação da Declaração Universal dos Direitos do Homem e do Cidadão, a Constituição alemã foi aprovada prevendo no seu Art. 1ㅇ. n. 1 que "a dignidade da pessoa humana é intangível. Respeitá-la e protegê-la é obrigação de todo o poder público". Seguindo a Constituição Alemã, a Constituição Portuguesa de 1976 e a Espanhola de 1978 também foram muito significativas no cenário da constitucionalização dos direitos da personalidade. Outros tratados internacionais também se seguiram à tendência de reconhecer de forma expressa a existência de direitos essenciais da pessoa humana, como o Pacto de San José da Costa, de 1969, que deu origem ao Sistema Interamericano de Direitos Humanos, do qual o Brasil faz parte.
} 
tegral da criança e "o respeito às suas opiniões, como garantido na Convenção dos Direitos da Criança e chancelado pelo Estatuto da Criança e do Adolescente".

A diferenciação entre personalidade e capacidade formal, na visão de Tepedino e Oliva ([2016-2020]) deve ser afastada em um sistema em que a personalidade e a dignidade da pessoa humana são os valores centrais do ordenamento jurídico e, como consequência, "as normas do Código Civil que disciplinam a titularidade e o exercício de direitos devem ser interpretadas tendo em conta a centralidade dos valores constitucionais, em especial a dignidade humana e a primazia das situações existenciais" ([2016-2020], p. 4).

Por isso, os autores defendem que o regime das incapacidades não deve ser aplicado às situações existenciais da mesma forma que aplicado nas situações patrimoniais, mas, tanto em uma quanto na outra deve-se atentar para que a limitação do poder decisório do menor não supere a proteção necessária e o torne prisioneiro. Por conseguinte, deve ser garantido ao menor o maior respeito possível às suas opções pessoais, ou seja, "os efeitos da incapacidade devem ser proporcionais à exata medida da ausência do discernimento, para que o intuito protetivo não se reverta em indevida supressão da autonomia do sujeito" (TEPEDINO; OLIVA, [2016-2020] p. 10). ${ }^{7}$

Nesse contexto, Borilho (2019) também critica a intervenção do Estado nos atos de escolha do indivíduo sobre o pretexto de garantir, mesmo contra a vontade do sujeito, a proteção do âmbito indisponível da sua humildade, como se o Estado fosse capaz de saber, melhor do o próprio sujeito, o que é digno ou indigno para ele. E continua criticando também a ideia de vulnerabilidade que, segundo ele, pode acabar impondo o que chamou de conservadorismo antiliberal ou ainda pode, em nome do próprio bem-estar do indivíduo, simplesmente decidir contra a vontade dele por considerar que ela seja "alienada" ou "ruim".

Atraindo essa mesma ideia para o contexto da incapacidade da criança para decidir sobre suas questões existenciais, a crítica do autor pode ser direcionada ao autoritarismo de pais ou de autoridades públicas que determinam sozinhos a decisão que supostamente meIhor corresponde ao interesse da criança, ignorando ou até mesmo contrariando o que a própria criança entende ser o melhor para os seus interesses, como se a vontade dela, pelo simples fato de ser menor de idade, necessariamente fosse uma vontade falha, alienada ou ruim. Foi justamente esta uma das críticas aos sistemas jurídicos internos dos países manifestadas pela Corte Interamericana de Direitos Humanos na já tratada Opinião Consultiva OC-17/2002.

Diante disso, parece adequado emprestar as palavras de Perlingieri (2002, p. 260) sobre a evolução gradual da pessoa e a intransmissibilidade de seus direitos humanos:

\footnotetext{
Uma das mais respeitáveis correntes que enfrentou o assunto71 teve seu nascedouro na Itália, delineada pela pena de Pietro Perlingieri, Pasquale Stanzione e Gaspare Lisella, havendo recebido nos últimos anos a adesão de civilistas brasileiros como Rose Melo Venceslau Meireles, Rafael Garcia Rodrigues, Ana Carolina Brochado Teixeira74 e Paulo Lôbo. Com a legítima preocupação de indevidamente transpor categorias e institutos do campo patrimonial para o existencial, esta doutrina reputa equivocada e acrítica a extensão da área de atuação do binômio capacidade jurídica-capacidade de agir, emerso no seio das relações patrimoniais, às situações jurídicas existenciais.75 O pressuposto da teoria bipartida das capacidades - diferenciação entre titularidade e exercício do direito - seria apto a configurar modelo perfeitamente justificável e aplicável no plano das situações jurídicas patrimoniais (MACHADO; NILSSON, 2016, p. 68).
} 
É necessário superar a rígida separação, que se traduz em uma fórmula alternativa jurídica, entre minoridade e maioridade, entre incapacidade e capacidade. A contraposição entre capacidade e incapacidade de exercício e entre capacidade e incapacidade de entender e de querer, principalmente, as relações patrimoniais, não corresponde à realidade: as capacidades de entender, de escolher, de querer são expressões da gradual evolução da pessoa que, como titular de direitos fundamentais, por definição nãotransferíveis a terceiros, deve ser colocada na condição de exercê-los paralelamente à sua efetiva idoneidade, não se justificando a presença de obstáculos de direito e de fato que impedem o seu exercício: o gradual processo de maturação do menor leva a um progressivo cumprimento a programática inseparabilidade entre titularidade e exercício nas situações existenciais.

Aqui se concorda com Perlingieri no sentido de que a expressão do que se quer e de quais são os interesses da pessoa é algo que vai se desenvolvendo gradualmente e que já está presente, ainda que em diferentes medidas, nas crianças. Logo, o exercício dos direitos pela própria criança, nas situações existenciais, deve ser a ela garantido de forma proporcional e progressiva ao desenvolvimento de sua maturidade.

A falibilidade do regime das incapacidades em situações existenciais e importância de que a criança possa determinar ou ao menos intervir naquilo que diz respeito ao seu modo de vida e seus direitos da personalidade ganha ainda mais relevância na atual sociedade da comunicação, na qual as crianças estão tão profundamente inseridas, representando grande parte dos usuários da rede mundial de computadores (DIAS; BOLESINA, 2019).

Nas últimas décadas tem sido marcante no mundo o fenômeno da globalização, que, segundo Hall (2006, p. 67), pode ser compreendido como um conjunto de processos de integração e conexão de comunidades e organizações em escala global, ultrapassando fronteiras nacionais e promovendo novas combinações de espaço e tempo. Tal fenômeno tornou-se ainda mais intenso com o advento da Internet, que tornou possível conectar simultaneamente pessoas dos mais variados lugares do planeta.

A Internet representa "um novo ambiente humano e tecnológico de expressão, informação e transações econômicas" (KAMINSKI, 2005, p. 40), que reúne pessoas de todos os lugares, com as mais diversas características para trocarem informações. Ela não é apenas uma tecnologia, mas o "meio de comunicação que constituiu a forma organizativa de nossas sociedades", tornando-se o coração de um novo paradigma que modifica todas as relações intersubjetivas (CASTELLS, 2003, p. 287).

Dias e Bolesina (2019) chamam a atenção para o fato de que não existem mais divisões nem barreiras entre as esferas virtuais e reais, uma vez que em ambos os ambientes são construídas e desenvolvidas relações humanas, de modo que os efeitos de determinadas ações em um mundo se estende ao outro.

Diante das transformações nas relações intersubjetivas trazidas pela Internet e o cenário volátil introduzido pelas novas tecnologias, os direitos da personalidade devem tomar novas fronteiras (OLIVEIRA; AMARAL, 2017).

Essas constantes transformações na sociedade revelam novas instâncias concernentes à personalidade do sujeito, não previstas nem previsíveis pelo legislador, de modo que estes interesses precisam ser tidos como uma categoria aberta. Assim, em que pesem os direitos da 
personalidade sejam taxativamente fundamentados na Constituição Federal e no Código Civil brasileiro (artigos 10 ao 21), como aqueles direitos subjetivos da pessoa de defender o que é próprio, seu: a vida, a integridade, a liberdade, a sociabilidade, a honra, a imagem, a privacidade, a autoria e outros mais, é preciso reconhece a proteção integral da personalidade, buscando a efetividade diante de tais mudanças (RIBEIRO; VINCE; NETTO, 2019)

A Internet, hoje, não é entendida apenas como uma forma de exposição do indivíduo, mas representa um ambiente de autoconhecimento e empoderamento, de construção e de afirmação da identidade. Nessa perspectiva, surge o denominado direito à "extimidade", que surge da necessidade do reconhecimento da "extimidade" como prática que transcende a mera autoexposição virtual.

Fala-se do sujeito que interage ininterruptamente com a tecnologia e com outras pessoas por intermédio de aparelhos eletrônicos, e que se vale dos últimos para expor a sua vida pessoal a terceiros. Essa postura, hoje naturalizada no seio social, está amparada em uma necessidade humana de usar a exposição para ser aceito, compreendido e reconhecido pelos demais internautas, revelando-se como uma faceta até então desconhecida da personalidade. Contudo, importa salientar que a Internet pode ser utilizada não apenas para promover o exibicionismo narcísico, mas também como forma de autoconhecimento e empoderamento através de uma relação dialógica com o outro, seu semelhante. Nesse cenário desponta a necessidade do reconhecimento da extimidade enquanto prática que transcende a mera autoexposição virtual ao visar à emancipação individual pela construção identitária contributiva (NASCIMENTO; BALEM, 2018, p. 2).

Na concepção de Machado (2003, p. 53), a identidade é uma construção psicológica na busca do conceito de si próprio e que está ligada tanto a uma perspectiva individual quanto a uma perspectiva social. Logo, a identidade envolve a concepção que uma pessoa tem de si mesma individualmente e em interação com os grupos sociais. Por essa razão, ela pressupõe pertencimento e compartilhamento de elementos da comunidade que são incorporados (SILVA JUNIOR; SILVA; AQUINO, 2014, p. 81). A identidade não envolve apenas a identificação do sujeito a determinados grupos e pessoas, mas também a diferenciação; afinal, cada um é o que é justamente por não ser outra coisa (LUCAS, 2012, p. 132).

A criança virtualizada, cada vez mais jovem já se dá conta de que existe à sua volta uma pluralidade de grupos sociais e progressivamente vai fazendo parte de vários deles; assim, a consciência de si mesmo, a construção de sua identidade começa a passar pela interiorização de uma gama cada vez maior e mais diversificada de papéis (AMANTE et al., 2014, p. 27), permitindo à criança direcionar sua conduta e construir sua identidade de formas diferentes (PECK, 2009, p. 223) e muito mais variadas do que aquelas que adotaria caso seus laços sociais fossem restritos ao ambiente familiar e escolar.

Trazendo novamente à baila a teoria do desenvolvimento da personalidade de Jung, o fato de a criança, pela Internet, desde muito nova, já construir vínculos com inúmeros ambientes diversos da família e da escola faz com que ela comece mais cedo seu processo de emancipação da psique dos pais e passe a desenvolver suas próprias aspirações. Já no âmbito sociológico, partindo do que defende Sen, a criança virtualizada tem maior acesso à informação, à educação, à cultura e, portanto, maior capacidade de se desenvolver e de contribuir com a sociedade. 
Como consequência disso, a criança inserida no universo virtual (que é tão real quanto o físico) tem condições de desenvolver sua personalidade mais rapidamente e de cada vez mais cedo manifestar o desejo de que sua voz seja ouvida e levada em consideração pelos adultos nas situações existenciais que Ihe digam respeito.

Desse modo, constata-se que a Internet e as transformações nas relações humanas provocadas por ela tornam ainda mais flagrante a insuficiência do sistema das incapacidades e da representação/assistência adotado pelo Código Civil para a efetiva tutela dos direitos da humanos e da personalidade da criança e do adolescente relativamente às questões existenciais e à necessidade de que as incapacidades sejam relidas e reinterpretadas a partir da ideia de desenvolvimento da personalidade e da pessoa humana.

\section{CONSIDERAÇÕES FINAIS}

Conclui-se que, tanto da perspectiva psicológica (Jung), quanto do ponto de vista sociológico (Sen), é importante que seja dado ao indivíduo liberdade para que ele possa buscar o próprio desenvolvimento psicológico e de suas capacidades, fazer suas próprias escolhas, se diferenciar do todo, e, assim, tornar-se um adulto com a psique saudável e que é capaz de contribuir com a sociedade, colaborar para o desenvolvimento do meio em que ele se encontra. Essa liberdade deve ser garantida desde a infância, o que implica afirmar que a criança deve ter liberdade de participar daquilo que diz respeito a seus direitos, especialmente nas situações existenciais.

Diante disso, deve-se realizar uma nova leitura e uma relativização da teoria das capacidades e da representação/assistência no Direito Civil no que diz respeito às situações existenciais, a fim de garantir que a criança possa participar do processo de tomadas de decisão que Ihe digam respeito ou que de algum modo a afetem, direito de ser ouvida e de ter sua voz levada em consideração, ampliando assim a efetividade de seus direitos humanos e especialmente de seus direitos da personalidade.

A capacidade jurídica não se confunde com a capacidade de exercício do direito ao livre desenvolvimento da personalidade por crianças e adolescentes, de modo que estes podem buscar a efetivação dos seus direitos da personalidade, inclusive contra condutas de seus próprios pais ou tutores, devendo, contudo, a questão ser analisada a partir da ponderação de valores e princípios tais como a capacidade do menor, o dever de cuidado, o melhor interesse da criança, a vulnerabilidade na Internet e a dignidade da pessoa humana.

\section{REFERÊNCIAS}

AMANTE, L.; MARQUES, H.; CRISTÓVÃO, M. R.; OLIVEIRA, C.; MENDES, P. O. Jovens e processos de construção de identidade na rede: o caso do Facebook. Educação, Formação \& Tecnologias, América do Norte, n. 7, p. 26-27, dez. 2014. Disponível em: http://www.eft.educom.pt/index.php/eft/article/view/414. Acesso em: 22 jun. 2020. BELTRÃO, S. R. Direito da personalidade: natureza jurídica, delimitação do objeto e relações com o direito constitucional. Revista do Instituto de Direito Brasileiro, Lisboa, a. 2, n. 1, p. 203-228, 2013. Disponível em: http:// www.cidp.pt/revistas/ridb/2013/01/2013_01_00203_00228.pdf. Acesso em: 20 jun. 2020.

BITTAR, C. A. Os direitos da personalidade. 7. ed. Rio de Janeiro: Forense Universitária, 2004.

BOLESINA, Iuri; SCHROEDER, Helena Carolina. A "limitação" voluntária dos direitos da personalidade no Direito Civil contemporâneo. In: SEMINÁRIO NACIONAL DE DEMANDAS SOCIAIS E POLÍTICAS PÚBLICAS NA SOCIEDADE CONTEMPORÂNEA, 12; MOSTRA NACIONAL DE TRABALHOS CIENTÍfICOS, 2., 2016. Santa Cruz do Sul. Anais [...], Santa Cruz do Sul: Universidade de Santa Cruz do Sul, 2016. 
BORGES, R. C. B.; SOUZA, A. S. L.; LIMA, I. M. S. O. A autonomia da criança intersexual: crítica à teoria jurídica das incapacidades. Revista EJJL, Joaçaba, v. 17, n. 3, p. 933-956, set./dez. 2016. Disponível em: https://portalperiodicos.unoesc.edu.br/espacojuridico/article/view/9548. Acesso em: 20 jun. 2020. DOI: https://doi.org/10.18593/ ejjl.v17i3.9548

BORILHO, D. A livre disposição de si: o mais fundamental dos direitos humanos. Revista Direitos Humanos $e$ Democracia, v. 7, n. 14, p. 7-14, 23 dez. 2019. Disponível em: https://www.revistas.unijui.edu.br/index.php/direitoshumanosedemocracia/article/view/9474. Acesso em: 29 abr. 2020. DOI: https://doi.org/10.21527/23175389.2019.14.7-14

CANTALI, F. B. Direitos da personalidade: disponibilidade relativa, autonomia privada e dignidade humana. Porto Alegre: Livraria do Advogado, 2009.

CASTELLS, M. Internet e sociedade em rede. In: MORAES, D. (org.). Por uma outra comunicação: mídia, mundialização cultural e poder. Rio de Janeiro: Record, 2003.

CORTE INTERAMERICANA DE DERECHOS HUMANOS (CORTE IDH). Condición jurídica y derechos humanos del niño. Opinión Consultiva OC-17/02 de 28 de agosto de 2002. Disponível em: http://www.corteidh.or.cr/docs/ opiniones/seriea_17_esp.pdf. Acesso em: 23 mar. 2020.

DIAS, F. V.; BOLESINA, I. O revenge porn no Brasil e as consequências da criminalidade digital para os direitos humanos de crianças e adolescentes: uma análise a partir das decisões do Superior Tribunal de Justiça. Revista Direitos Humanos e Democracia, v. 7, n. 14, p. 107-127, dez. 2019. Disponível em: https://www.revistas.unijui. edu.br/index.php/direitoshumano se democracia/article/view/6953. Acesso em: 13 abr. 2020. DOI: https://doi. org/10.21527/2317-5389.2019.14.107-127

FERMENTÃO, C. A. G. R. Direito e axiologia - o valor da pessoa humana como fundamento para os direitos da personalidade. Revista Jurídica Cesumar, Maringá, v. 7, n. 1, p. 57-80, jan./jun. 2007.

FERNANDES, C. M.; BORCAT, J. C. A proteção da personalidade na era digital. In: SIQUEIRA, D. P.; RUIZ, I. A. (org.). Acesso à justiça e os direitos da personalidade. Birigui, SP: Boreal, 2015. p. 82-105.

GODINHO, A. M.; GUERRA, G. R. A defesa especial dos direitos da personalidade: os instrumentos de tutela previstos no Direito brasileiro. Revista Jurídica Cesumar, Maringá, v. 13, n. 1, p. 179-208, jan./jun. 2013. Disponível em: https://periodicos.unicesumar.edu.br/index.php/revjuridica/article/view/2440. Acesso em: 10 maio 2020.

HALL, S. A identidade cultural na pós-modernidade. 11. ed. São Paulo: Martins Fontes, 2006.

JUNG, Carl Gustav. O desenvolvimento da personalidade. Tradução de Frei Valdemar do Amaral. Petrópolis/RJ: Vozes, 2011.

KAMINSKI, O. (org.). Internet legal: o direito na tecnologia da informação: doutrina e jurisprudência. Curitiba: Juruá, 2005.

LEITE, C. H. B. Os direitos da personalidade na perspectiva dos direitos humanos e do direito constitucional do trabalho. Revista Brasileira de Direito Constitucional, São Paulo, n. 7, v. 2, p. 342-354, jan./jun. 2006.

LUCAS, D. C. A identidade como memória biográfica do corpo e sua proteção jurídica: itinerários de um paradoxo. Sequência, Florianópolis, n. 65, p. 125-154, dez. 2012. Disponível em: http://www.scielo.br/scielo.php?scrip$\mathrm{t}=\mathrm{sci}$ _arttext\& pid=S2177-7055201 2000200007\&Ing=en\&nrm=iso. Acesso em: 16 jun. 2020.

MACHADO, D. C.; NILSSON, A. Capacidade de agir e direitos da personalidade no ordenamento jurídico brasileiro: o caso do direito à privacidade. Revista Brasileira de Direito Civil, Belo Horizonte, v. 8, p. 47-80, abr./jun. 2016. Disponível em: https://rbdcivil.ibdcivil.org.br/rbdc/article/view/64. Acesso em: 10 maio 2020.

MACHADO, H. V. A identidade e o contexto organizacional: perspectivas de análise. Revista de Administração Contemporânea. Curitiba, v. 7, n. especial, p. 51-73, 2003. Disponível em: http://www.scielo.br/scielo.php?scrip$\mathrm{t}=\mathrm{sci}$ arttext\&pid=S1415-65552003000500004\&ln g=en\&nrm=iso. Acesso em: 13 jul. 2019.

NASCIMENTO, V. R.; BALEM, I. F. O reconhecimento do direito à extimidade na sociedade em rede: desafios e limites ao fortalecimento da identidade de gênero não binária. In: SEMANA ACADÊMICA DA FADISMA, 15., 2018. Santa Maria. Anais [...]. Santa Maria, RS: Fadisma, 2018. Disponível em: http://sites.fadisma.com.br/entrementes/anais/wp-content/uploads/2019/04/o-reconhecimento-do-direito-a-extimidade-na-sociedade-em-rede. pdf. Acesso em: 15 mar. 2020.

OLIVEIRA, J. V. M.; AMARAL, M. F. T. P. T. Direito ao esquecimento e a autodeterminação informativa. In: SIQUEIRA, D. P.; AMARAL, S. T. (org.). Democracia, cidadania e direitos da personalidade. 1. ed. Birigui, SP: Boreal, 2017. p. 170-197.

PECK, P. Quando a sociedade muda, o direito também deve mudar. In: KAMINSKI, Omar. Internet legal: o direito na tecnologia da informação. 1. ed. Curitiba: Juruá, 2009. 


\section{Democracia}

PEDERSOLI, R. B. Jung e a experiência religiosa: um processo fundamental no desenvolvimento psicológico na visão da psicologia analítica. 2018. Dissertação (Mestrado em Ciência da Religião) - Pontifícia Universidade Católica de São Paulo, São Paulo, 2018.

PERLINGIERI, P. Perfis do direito civil: introdução ao direito civil constitucional. 2. ed. Tradução Maria Cristina de Cicco. Rio de Janeiro: Renovar, 2002.

PINHEIRO, J. D.; SOUSA, S. M. Uma avaliação da criança como sujeito assujeitado no processo judicial. Avaliação Psicológica, São Paulo, v. 2, n. 19, p. 205-212, 2020.

POMPEU, G. V. M.; MELO, R. V. C. A contraditória relação entre livre-mercado e desenvolvimento humano: possíveis soluções a partir do conceito de capacidades em Amartya Sen. Direito, Estado e Sociedade, n. 49, p. 188207, jul./dez. 2016.

RAMOS, L. M. A. Apontamentos sobre a psicologia analítica de Carl Gustav Jung. ETD - Educação Temática Digital, Campinas, v. 4, n. 1, p. 110-144, dez. 2002.

REIS, J. R.; BOLESINA, I. A disponibilidade (no exercício) dos direitos da personalidade como deferência à dignidade humana no direito civil constitucionalizado. Revista Em Tempo, v. 14, p. 11-30, mar. 2016. ISSN 1984-7858. Disponível em: https://revista.univem.edu. br/emtempo/article/view/1287. Acesso em: 30 jun. 2019.

RIBEIRO, D. G. M.; ÁVILA, G. N.; SANTOS, M. O sistema interamericano e o direito da criança em prestar declarações no processo penal: garantias para reconhecimento de sua personalidade. Revista Jurídica Cesumar, Maringá, v. 17, n. 3, p. 891-915, 2017. DOI: http://dx.doi.org/10.17765/2176-9184.2017v17n3p891-915. Acesso em 12 fev. 2020.

RIBEIRO, D. M.; VINCE, F. N.; NETTO, J. P. G. Acesso à justiça: a tutela coletiva de direitos individuais homogêneos e dos direitos da personalidade. Revista Juris Poiesis, Rio de Janeiro, v. 22, n. 30, p. 264-282, 2019. ISSN 24480517. Disponível em: http://periodicos.estacio.br/index.php/jurispoiesis/article/viewFile/7617/47966414. Acesso em: 20 jan. 2020.

SANI, A. I. Reflexões sobre infância e os direitos de participação da criança no contexto da justiça. e-cadernos CES, [on-line], n. 20, p. 75-89, 2013. Disponível em: http://journals.opene dition. org/eces/1668. Acesso em: 15 maio 2020.

SEN, Amartya. Desenvolvimento como liberdade. São Paulo: Companhia das Letras, 2010.

SILVA JUNIOR, J. F.; SILVA, L. K. R.; AQUINO, M. A. Comunidades virtuais de música como subsídio para a construção da identidade afrodescendente. Perspectivas em Ciência da Informação, Belo Horizonte, v. 19, n. 1, p. 75-89, mar. 2014. Disponível em: http://www.scielo.br/ scielo. php?script=sci_arttext\&pi$\mathrm{d}=\mathrm{S} 1413-9362014000100006 \&$ Ing=en\&nrm=iso. Acesso em: 25 jul. 2019.

SZANIAWSKI, E. Direitos de personalidade e sua tutela. São Paulo: Revista dos Tribunais, 2005.

TEPEDINO, G.; OLIVA, M. D. Personalidade e capacidade na legalidade constitucional. In: MENEZES, J. B. de (org.). Direito das pessoas com deficiência psíquica e intelectual nas relações privadas: Convenção sobre os direitos da pessoa com deficiência e Lei Brasileira de Inclusão. Rio de Janeiro: Progresso, 2016. p. 227-248. Disponível em: https://www.academia.edu/30890584/Personalidade_e_capacidade_na_legalidade_constitucional. Acesso em 13 abr. 2020.

UNICEF. Convenção sobre os Direitos da Criança. 20 de novembro de 1989. Nova York, EUA. Disponível em: www. unicef.org/brazil/convencao-sobre-os-direitos-da-crianca. Acesso em: 10 fev. 2020.

ZAMBAM, N. J. A teoria da justiça de Amartya Sen: liberdade e desenvolvimento sustentável. Tese (Doutorado) Programa de Pós-Graduação em Filosofia da Pontifícia Universidade Católica do Rio Grande do Sul, Porto Alegre, 2009. 